\title{
Fine mapping of a strong QTL of field resistance against rice blast, Pikahei-1(t), from upland rice Kahei, utilizing a novel resistance evaluation system in the greenhouse
}

\author{
Xin Xu $\cdot$ H. Chen $\cdot$ T. Fujimura $\cdot$ S. Kawasaki
}

Received: 25 January 2008 / Accepted: 21 June 2008 / Published online: 29 August 2008

(C) The Author(s) 2008. This article is published with open access at Springerlink.com

\begin{abstract}
Field resistances (FR) against rice blast are highly evaluated by breeders for their durability, in contrast to the conspicuous but often less durable true resistances. However, lack of efficient systems for evaluation of resistance has delayed their practical application. Kahei, an upland domestic cv., is known for its very high FR against rice blast. We fine-mapped its highest quantitative trait loci (QTL), qBFR4-1, using residual heterozygosity of recombinant inbred lines (RILs) and our semi-natural rice blast inoculation/evaluation system in the greenhouse, with comparable accuracy to the true resistance genes. This system enabled reproducible high-density infection, and consequently allowed quantification of the resistance level in individual plants. The target region was first narrowed down to about $1 \mathrm{Mb}$ around at $32 \mathrm{Mb}$ from the top of chromosome 4 in the Nipponbare genome, with the upland evaluation system assessing the $\mathrm{F}_{7}$ generation of Koshihikari (lowland, FR: very weak) $\times$ Kahei (upland, FR: very strong)
\end{abstract}

Communicated by Q. Zhang.

X. Xu $\cdot$ H. Chen $\cdot$ S. Kawasaki $(\bowtie)$

Division of Plant Sciences, National Institute of Agrobiological Sciences, Kannon-dai 2-1-2, Tsukuba, Ibaraki 305-8602, Japan e-mail: kawasa@nias.affrc.go.jp

\section{$\mathrm{X} . \mathrm{Xu} \cdot \mathrm{T}$. Fujimura}

Laboratory of Plant Genetic Engineering,

Graduate School of Life and Environmental Sciences,

University of Tsukuba, Tennoudai 1-1-1, Tsukuba,

Ibaraki 305-8572, Japan

e-mail: bioxuxin@affrc.go.jp

Present Address:

H. Chen

Department of Plant Science,

Macdonald Campus of McGill University, 21111 Lakeshore Road,

Sainte-Anne-De-Bellevue, QC, Canada H9X 3V9
RILs. Then, $F_{9}$ plants $(4,404)$-siblings of hetero $F_{8}$ plants at the region-were inoculated with rice blast in a greenhouse using the novel inoculation system, and individual resistance levels were diagnosed for fine QTL analysis and graphical genotyping. Thus, the resistance gene was finemapped within $300 \mathrm{~kb}$ at $31.2-31.5 \mathrm{Mb}$ on chromosome 4, and designated Pikahei-l(t). By annotation analysis, seven resistance gene analog (RGA) ORFs of nucleotide-bindingsite and leucine-rich-repeat (NBS-LRR)-type were found in the center of the region as the most likely candidate counterparts of the resistance gene. This is similar in structure to the recently reported Pik cluster region, suggesting that most of the other dominant QTLs of the FRs may have similar RGA structures.

\section{Introduction}

As disease control of crops is now being required to reduce both environmental and labor costs, as well as to secure food safety, breeding control with disease resistance genes seems to have better prospects than chemical control, although even the latter is also shifting toward the use of inducers of plant resistance, such as probenazole (Iwata et al. 2004). Resistance against plant diseases can be classified roughly into two types: complete (qualitative) or true resistance and partial (quantitative) or field resistance (FR) (Ezuka 1972), although these respective groups of definition are not completely overlapping. These resistances were studied extensively in rice against its most serious disease, rice blast disease caused by Magnaporthe oryzae. True resistance is effective in a very clear-cut way against blast isolates with the corresponding avirulence gene, but often very vulnerable to mutations of that avirulence gene, especially in modern large scale monoculture systems. On the 
other hand, in most cases although FR allows slight blast infection, it shows effective suppression of outbreaks and such varieties are highly valued for their durability (Bonman 1992).

To attain durability, breeding with true resistances genes requires rather complicated strategies, such as multi-line or gene pyramiding. Although the Koshihikari-BL multi(NIL-)line project, which began in 2005 (Ishizaki et al. 2005) and covers the whole of Niigata prefecture, is having good success at present, it requires a well-organized breeding and race monitoring system and complicated line management, and it is still too early to draw definitive conclusions regarding its success. Most FR consists of multiple quantitative trait loci (QTLs), and reconstruction of FR with their combinations is difficult even with the aid of molecular markers because of the absence of an efficient and accurate assay system. Although there have been some reports of greenhouse assays of FR (Hayashi 2005), the main system used for assaying FR is field diagnostic testing, which requires a large area for replication and can be performed only once a year. Therefore, fine mapping or cloning is difficult, and to date only one recessive blast FR gene has been cloned (Fukuoka et al. 2007).

"Kahei" is a domestic upland rice cv. found in southern Kyushu, which has very strong FR. Analysis of $F_{2}$ plants with $\mathrm{F}_{3}$ progeny of Kahei $\times$ Koshihikari identified $q B F R 4-1$ as the most highly contributing QTL of rice blast resistance located on the long arm of chromosome 4 (Miyamoto et al. 2001).

As a first step in its fine mapping, we analyzed a sibling population from those with residual heterozygosity in the QTL region in recombinant inbred lines (RILs), using the upland late-sowing field assay and localized it within about $2.2 \mathrm{Mb}$. This gene was tentatively named Pikahei-l $(\mathrm{t})$, because of confusion regarding the still-formal numbering system of $P i$ genes. To increase the efficiency and accuracy of the mapping data, we utilized our newly developed blast resistance assay system in the greenhouse (Kawasaki et al. 2008), mimicking the natural infection, by placing the testing plants for 4-7 days in an inoculation tent in a greenhouse, with diseased plants as the source of spores. With this system, we could diagnose the symptoms or phenotypes of the individual plants in ten grades, and QTL analysis was performed. Further refining of the conditions allowed the graphical genotyping of close recombinant individuals. Using this novel resistance evaluation system in $4,404 \mathrm{~F}_{8}$ heterozygous siblings of RI lines in the greenhouse, we could narrow down the Pikahei-1(t) gene region to within $\sim 300 \mathrm{~kb}$. The cluster of NBS-LRR type RGAs found in the center of the region was consistent with our hypothesis that identity of the most of FR components may be the weak type of these resistance (R-) genes.

\section{Materials and methods}

Plant and fungal materials

A set of $\mathrm{F}_{4}$ RILs of Koshihikari (lowland, FR very weak) $\times$ Kahei (upland, FR very strong) with heterozygosity only in the strongest QTL $q B F R 4-1$, and homozygous in other QTL, $q B F R 4-2$, and $q B F R 4-3$ (Miyamoto et al. 2001), along with the parental strains Kahei and Koshihikari were kind gifts from Dr Miyamoto and Dr Hirasawa of the Agricultural Research Institute, Ibaraki Agricultural Center (Mito, Ibaraki, Japan). From the $\mathrm{F}_{6}$ generation, siblings of the above RILs, which were confirmed to be heterogeneous at $q B F R 4-1$, a total of $400 \mathrm{~F}_{7}$ lines were obtained, and these lines were planted in a segregated upland field in June 2003 at the National Institute of Agrobiological Sciences (NIAS) Tsukuba, Japan, for field diagnosis as described in the following section.

For greenhouse diagnosis, the $\mathrm{F}_{7}$ lines segregating resistant/susceptible on upland field, set on heterozygous $F_{6}$ at $q B F R 4-1$, were grown in a lowland field to propagate $\mathrm{F}_{8}$ seeds. For genotyping of $q B F R 4-1$, about $60 \mathrm{~F}_{8}$ lines (34 seeds each; $F_{9}$ generation) were sown in the grain-seeding mats of a $17 \times 34$ hole matrix with resistant (Kahei) and susceptible (Koshihikari) reference lines, and checked for the line's heterozygosity in the greenhouse, as described in the following section. The seeds $\left(\mathrm{F}_{9}\right)$ of the hetero-confirmed $\mathrm{F}_{8}$ lines were later utilized for large-scale screening of close recombinants around the target $q B F R 4-1$ locus. Standard cv. Nipponbare was obtained from the NIAS Gene Bank.

The rice blast isolate Kyu9439013 (047.0) was a kind gift from Dr N. Hayashi of NIAS.

Diagnosis of blast resistance in the field

Field resistance diagnosis was first made in the segregated upland field by late sowing of the seeds around mid-June. Field diagnosis of the RI lines of $F_{6}$ to $F_{7}$ generations was done as follows. For each $\mathrm{F}_{6}$ individual thought to be heterozygous at $q B F R 4-1$, around 20 lines $\mathrm{F}_{7}$ were selected and their seeds (about 20 grains of $\mathrm{F}_{8}$ for each $\mathrm{F}_{7}$ line) were sown in a line $40 \mathrm{~cm}$ in length in the segregated upland field as shown in Fig. 1. The line interval was $20 \mathrm{~cm}$, and each of 20 lines was accompanied by reference lines of Kahei ( $\mathrm{R}$ resistant) and Koshihikari ( $\mathrm{S}$ susceptible). This set of 22 lines constituted a unit of testing lines, roughly corresponding to an $\mathrm{F}_{6}$ parent. Four such sets comprised one row and the total field accommodated about ten rows. The test was performed with two repeats (in two population), i.e. 20 sets of $F_{6}$ corresponding to 400 lines of $F_{7}$ were tested in duplicate; in total, 800 of $\mathrm{F}_{8}$ lines were tested. As spore spreaders, a line of Koshihikari was placed 
$18 \mathrm{~m}$ contains 4 units in a row

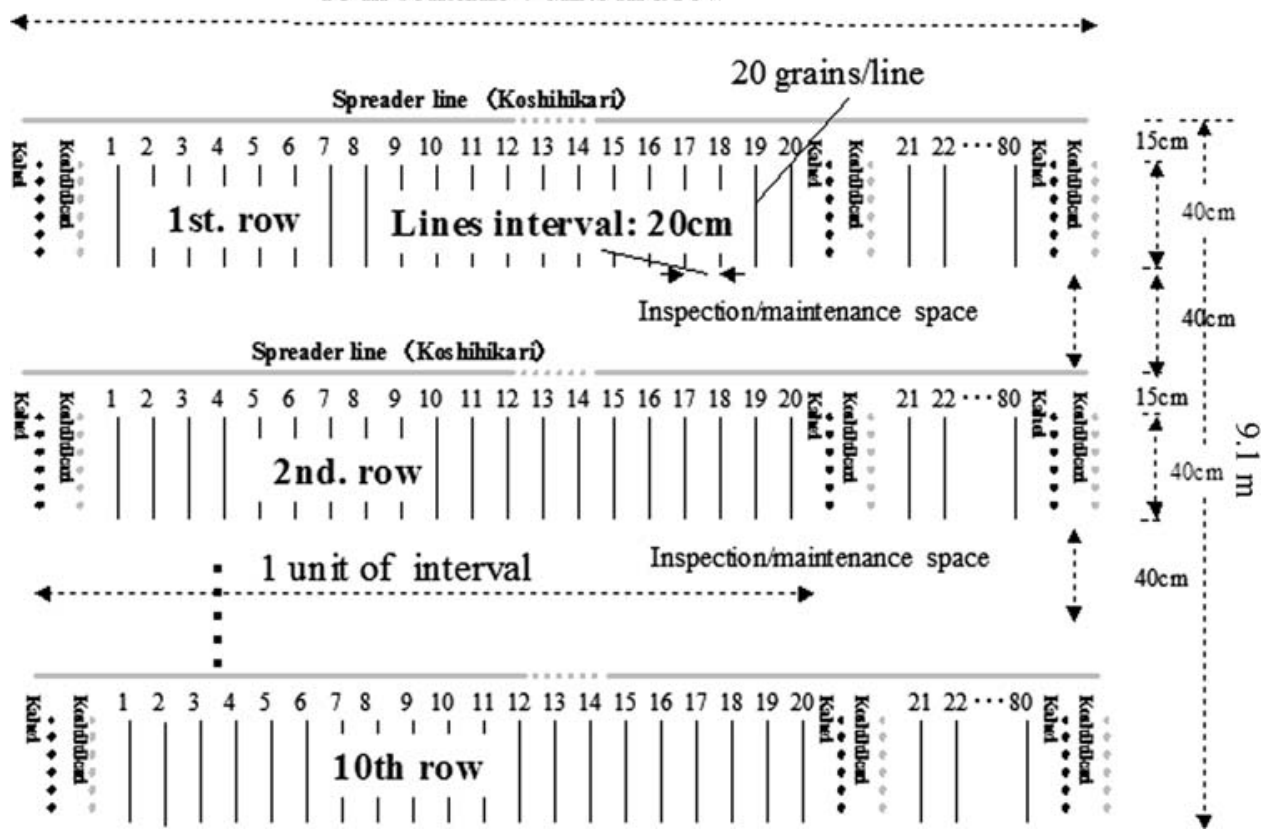

Fig. 1 Field rice sowing scheme for diagnosis of field resistance in a segregated upland field. North is to the top of the figure. In mid-June 2003, samples of about 20 grains of each $F_{8}$ generation were sown in a line $40 \mathrm{~cm}$ in length. Each line represents the sibling population of an $\mathrm{F}_{7}$ plant. Diagnoses were made for these $\mathrm{F}_{7}$ lines and not for the $\mathrm{F}_{8}$ individuals, because the susceptibility was discernible only as lines. Each row was from four units, consisting of 20 test lines and $\mathrm{R}$ (Kahei) and

at the north rim of each testing row, apart $15 \mathrm{~cm}$ from the rim, and the total field was circled with three lines of Koshihikari spreaders. By diagnosing the symptoms of the unit lines of $\mathrm{F}_{7}$ by overviewing three times from September to October, the heterozygous $\mathrm{F}_{6}$ sets were identified as a population segregating $\mathrm{R}$ and $\mathrm{S}$ in $\mathrm{F}_{7}$ lines. Only the obviously susceptible $\mathrm{F}_{7}$ lines in the segregating $\mathrm{F}_{6}$ sets, and allsusceptible $\mathrm{F}_{6}$ sets were selected for DNA analysis for fine mapping. In this protocol, the plant density was lower than in conventional field diagnosis methods. Therefore, the seeds of the important lines were harvestable in autumn even from the susceptible lines.

The leaves of apparently susceptible lines were harvested and their DNA was extracted using a Kurabo NA2000 DNA isolation machine (Kurabo, Osaka, Japan), and then the genotypes of the neighboring DNA markers were analyzed with the High Efficiency Genome Scanning (HEGS) system (Nihon Eido, Tokyo, Japan) as described previously (Xu et al. 2005).

Diagnosis of blast resistance in the greenhouse

Greenhouse diagnosis of blast resistance was performed according to the newly developed semi-natural inoculation system for screening of blast-resistant mutants (Kawasaki
$\mathrm{S}$ (Koshihikari) reference lines at the ends. Each row was accompanied with a spore spreader line of Koshihikari of about the same density as the test lines. Ten rows were surrounded by three lines of Koshihikari spreaders. No artificial spreading of blast was done. The diagnosis was performed three times around the seed maturation time at half-month intervals

et al. 2008), in a greenhouse with a controlled temperature of $17-27^{\circ} \mathrm{C}$ with a day length of $14 \mathrm{~h}$ supplemented with fluorescent lamps in winter. For inoculation, 2- to 3-weekold seedlings, prepared in grain-seeding mats, were covered in a tent for 4-6 days with a blast-infected seedling mat as a source of inoculating spores at the center, in a pool accommodating up to nine such mats. Daily temperature fluctuation of more than $5-7^{\circ} \mathrm{C}$ was important to secure sufficient dew formation at night. After inoculation, the tent was removed and seedlings were grown under the same conditions for a further $2-3$ weeks to allow symptoms to develop fully. The inoculated plants were diagnosed on a scale of $0-10$ by evaluating symptoms as described in the manual by Hayashi (2005) or as shown in Table 1 around 20 days after inoculation. Conventional spray inoculation as a control was performed according to the standard protocol (Hayashi 2005) for seedlings of the same age as above at a conidia concentration of $3 \times 10^{5} / \mathrm{ml}$ with incubation for $24 \mathrm{~h}$ in a humid chamber at $25^{\circ} \mathrm{C}$ at a relative humidity of $100 \%$, but diagnosis was made at 3 weeks after inoculation.

The $\mathrm{F}_{9}$ generation seedlings obtained from heterozygous $\mathrm{F}_{8}$ lines, which were confirmed by checking the genotypes of flanking markers and segregation of the resistant and susceptible individuals, were inoculated with the rice blast race Kyu9439013 (047.0). 
Table 1 Diagnosis table of the symptoms of blast-infected individual rice seedlings 3 weeks after inoculation with semi-natural spores spread for 5 days in a humidity-saturated tent

\begin{tabular}{clc}
\hline Scores & \multicolumn{1}{c}{ Symptoms of the plants } & Diagnosis \\
\hline 0 & No blast lesions & \\
1 & Small brown specks the size of pinpoints were observed & Resistant \\
2 & Small brown specks were observed & \\
3 & Significant numbers of small brown specks were observed & \\
4 & Larger brown specks were observed & \\
5 & Significant numbers of larger brown specks were observed & Susceptible \\
6 & Large progressive blast lesions were observed & \\
7 & Leaf tips dying with blast & \\
8 & Single leaf of a plant died with blast & \\
9 & A few leaves of a plant died with blast & \\
10 & Almost the whole plant died &
\end{tabular}

The 3-week-old rice seedling mats in a water-pool were covered with a transparent vinyl or polyethylene tent with a mat of diseased plants as the inoculation seeds. The level of infection was diagnosed 3 weeks after inoculation. Symptom grades 1-6 were determined by the infected leaves that had developed during the period of inoculation, and grades 7-10 were analyzed by the symptoms of whole diseased plants at a glance. The threshold for diagnosis as R or S, here between 5 and 6, was selected to be consistent with the results of graphical genotyping

\section{Genotyping}

DNA was extracted from leaves $2 \mathrm{~cm}$ in length from seedlings at the age of approximately 1 week after sowing by a high-throughput CTAB method (Xu et al. 2005). From the selected close recombinants, samples of approximately $5 \mu \mathrm{g}$ of DNA were re-extracted (1 $\mathrm{g}$ fresh weight) using a Kurabo NA2000 DNA isolation machine. Thirteen SSR markers from IRGSP (The International Rice Genome Sequencing Project 2005) and Gramene (http://www. gramene.org/) were analyzed with the HEGS system (Nihon Eido, Yushima, Tokyo, Japan) as described previously (Xu et al. 2005), and six single nucleotide polymorphism (SNP) markers were subjected to single strand conformation polymorphism analysis in an HEGS system (HEGS-SSCP; Xu et al., in preparation) setting the gel running temperature at $6-8^{\circ} \mathrm{C}$ with cooling jackets (Nihon Eido) connected in tandem to a water cooler/circulator.

Fine QTL analysis

Quantitative trait loci analysis was performed with Windows QTL Cartographer V2.5 (Wang et al. 2006) via single marker diagnosis of the leaf symptoms as grade 0-10 described in Table 1. To clarify the fine structure of QTL, data of the close recombinants between markers flanking the target gene were used. The map addresses in megabases were taken from the marker location on chromosome 4 from IRGSP and Gramene. A minimum LOD (logarithm of the odds) threshold of 2.5 was used to indicate significance.
Physical map construction

The physical locations of SSR markers and ORFs were determined in the Gramene marker database (http://www. gramene.org/) and RiceGAAS analysis in RGP (http:// ricegaas.dna.affrc.go.jp/), respectively, in correlation with the close recombinant map constructed as described above and graphical genotyping of the markers. The physical map was constructed on the basis of that of Nipponbare from IRGSP (http://rgp.dna.affrc.go.jp/IRGSP/), again in correlation with the results of close recombinants analyses. The ORFs were also localized on the physical map if SNPs were detected between the parents, to correlate the results with the graphical genotypes.

\section{Construction of fine SNP markers}

Within the physical map, novel markers were constructed by checking the target bacterial artificial chromosome (BAC) clones or ORF sequences in IRGSP (ssp. japonica cv. Nipponbare, http://rgp.dna.affrc.go.jp/IRGSP/) by BLAST analysis (http://www.ncbi.nlm.nih.gov) against the complete rice genome sequence. Sequences found to be unique in the genome were used to design primers with Primer3 (http://fokker.wi.mit.edu/cgi-bin/primer3/primer3_www.cgi). Rather longer PCR product size, around $1.5 \mathrm{~kb}$, was preferred to detect more SNPs. The uniqueness of each primer in the genome was again confirmed by BLAST analysis.

PCR fragments amplified from the parent cvs. and confirmed to be single-banded on $1 \%$ agarose gels were 
directly sequenced using an ABI BigDye ${ }^{\circledR}$ Terminator v3.1 Cycle Sequencing Kit and ABI 3100 DNA sequencer (Applied Biosystems, Foster City, CA, USA) to detect SNPs between parents. The confirmed SNPs were selected to redesign HEGS-SSCP primers with Primer3 to obtain a suitable PCR product size (100-300 bp). As far as possible, the SNP was positioned in the center although we did not observe a significant "position effect" during HEGS-SSCP electrophoresis.

\section{Results}

Mapping of $q B F R 4-1$ by upland field evaluation of the heterozygosity-remaining population at the locus

The most contributing locus to blast resistance in Kahei, qBFR4-1, was fine-mapped with an upland late sowing field test. Seeds of the $\mathrm{F}_{8}$ generation from $400 \mathrm{~F}_{7}$ lines obtained from 20 parents $\left(\mathrm{F}_{6}\right.$ generation) with residual heterozygosity at $q B F R 4-1$ but homozygous (mostly susceptible) at other QTLs, $q B F R 4-2$ and $q B F R 4-3$, were sown in duplicate as shown in Fig. 1 in a segregated upland field for blast resistance evaluation. The sowing protocol was sparser than in the conventional system (Ezuka 1972) to secure harvesting of seeds even from the susceptible lines. The phenotypes of the $\mathrm{F}_{7}$ lines were diagnosed by overviewing the corresponding lines in the field, and 96 clearly susceptible lines were checked for their DNA markers around the $q B F R 4-1$. From the results of graphical genotyping of the close recombinants around the target region, the target locus was narrowed down to a region of $32-33 \mathrm{Mb}$ of Chromosome 4 (http://www.gramene.org), close to the end of the long arm, in the Nipponbare physical map (refer to Fig. 3). However, further narrowing down of the locus was difficult because of the unstable field condition in the subsequent years, probably due to repeated upland cultivation of rice. As these mapping data indicated that this blast resistance was due to a single resistance gene, it was named Pikahei-1(t) - the Pi-numbering system was avoided due to present confusion due to several uncontrolled gene reports and lack of information of the gene origin and their clustering.

Diagnosis with a semi-natural blast spore inoculating system in a greenhouse

To increase the accuracy of mapping for gene cloning, a novel greenhouse blast semi-natural inoculation and diagnosis system, developed for recessive mutant screening (Kawasaki et al. 2008), was applied for fine mapping of Pikahei-1(t). The main difficulty in diagnosing field or quantitative resistance against rice blast in the greenhouse by conventional spray inoculation with conidia suspension is that the reproducing high density of lesion development is often difficult even with a concentrated conidia suspension. The novel system described here mimics natural infection by covering the test seedlings with a lesion-developing rice mat as a spore source in a tent for 5-7 days in a greenhouse. With this system, a far great number of lesions developed per leaf within a few weeks from the start of covering (Fig. 2), thus enabling fine quantification of the blast resistance of the rice strains. Only covering in a tent without diseased mat after spray inoculation resulted in far less lesion numbers especially on the main targer of 3rd4th leaves, less than even the conventional humid chamber inoculation, indicating that natural conidia spreading is the key source of infection (Fig. 2).

For fine mapping of the Pikahei-1(t) gene, siblings of the residual heterozygotes at this locus were tent-inoculated as described above with the diseased seedling mat infected with the race Kyu9439013. Twenty-one days after commencement of infection, the symptoms of the leaves were diagnosed on the original scale shown in Table 1, which was constructed from observation of these inoculated populations. The phenotype was clear and consistent with the results of genotyping of markers close to the target region. This system was both consistent and efficient, and valid even in the middle of summer or winter, seasons that are not optimal for conventional spray inoculation, even with the presence of air conditioner.

From the lowland field-propagated plants $\left(\mathrm{F}_{8}\right)$, lines heterozygous for Pikahei-1 $(\mathrm{t})$ were selected in this system as lines with segregation of susceptible individuals at a ratio of $1 / 4$. The siblings from these confirmed heterozygous $\mathrm{F}_{8}$ lines, a total of 2,965 seedlings $\left(\mathrm{F}_{9}\right)$, were used for diagnosis of the phenotypes and genotyping of the neighboring markers. These lines were mostly homozygous in the genome except the target region, enabling stable phenotype assessment.

Fine QTL map and physical map around Pikahei-1(t)

To increase the accuracy of the target region, QTL analysis was performed for the 616 individuals among the above $2,965 \mathrm{~F}_{9}$ lines with recombination between the distant flanking markers RM6748 and RM1153, identified from field diagnosis as described earlier. QTL analysis with the data obtained as described above revealed a sharp single peak around $31.2-31.5 \mathrm{Mb}$ on chromosome 4 between the markers RM 17496 and RM6629, and RM5473 at the crest; peak LOD score of 33 and half height width of about $1 \mathrm{Mb}$ (Fig. 3). This was also consistent with the expectation that a single gene is responsible for the resistance. The asymmetry of the peak was due to the occurrence of a recombination event on the left side some generations prior to the diagnosed population. Despite selecting the recombined 
A

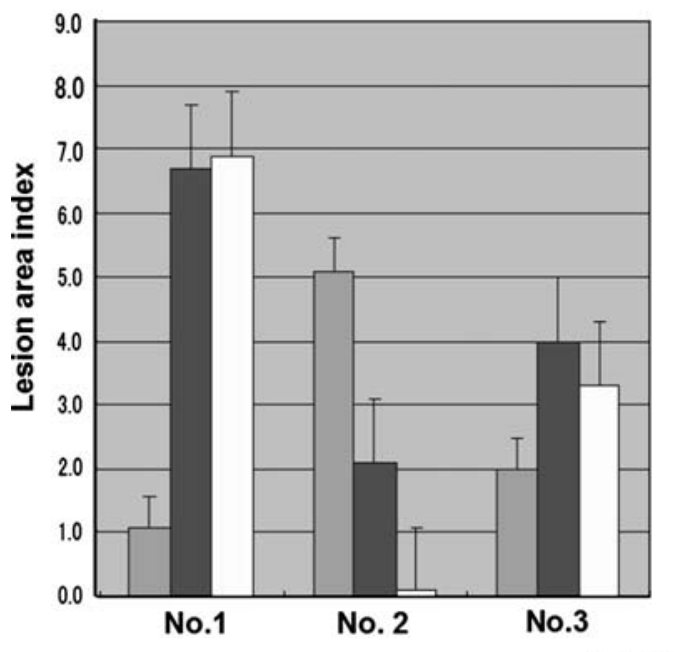

B

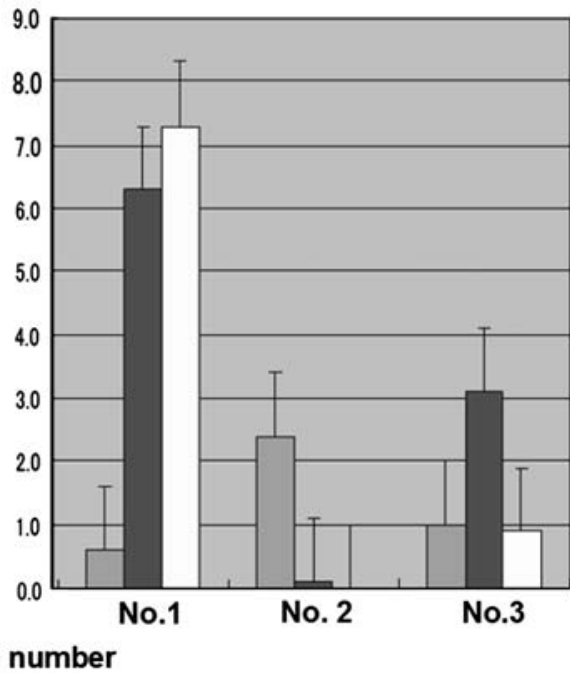

Fig. 2 Comparison of leaf blast development in rice seedlings inoculated with the novel semi-natural infection system and conventional spray inoculation. Rice seedlings in the sowing mats were inoculated with the different systems at 2 weeks of growth in a greenhouse after sowing, and the symptoms were checked on the 3rd week. The lesion area index was determined with a field resistance diagnosis system $(0$ no lesion to 10 died out) as described in the Hayashi manual (2005) for the 2nd, 3rd, and 4th leaves, and the results are shown in histograms with standard deviation bars of left (gray), center (black), and right (white), respectively, in each group. Blast fungal race was Kyu9439013 (047.0). A: cv. Koshihikari. B: cv. Nipponbare. Sample No. 1: novel semi-natural inoculation system, 3 weeks from starting of 5 days of covering in the inoculation tent with the lesion-developed plants as an inoculation seed. No. 2: spray inoculated as in no. 3, but kept in the inoculation tent as no. 1 without diseased plants. No. 3: infected by the conventional spray inoculation system with a suspension of $3 \times 10^{5}$ conidia/ml, and kept for $24 \mathrm{~h}$ in the humid chamber

et al. 2003) and a QTL from the Oryza rufipogon referred as Pi37 by Hirabayashi et al. (2005), indicated as $q B R o r(\mathrm{t})$ in Fig. 3.

\section{Graphical genotyping}

Although graphical genotyping with the above close recombinants was mostly consistent with the results of QTL analysis, there were slight contradictions in phenotypes (data not shown). Therefore, an additional experiment was performed with more refined conditions of elongated infection period and temperature control with 1,495 heterosiblings of the $F_{9}$ generation. A very consistent graphical genotype was constructed based on the results of this experiment, as shown in Fig. 4. From these data, the Pikahei-1(t) gene was delineated again between the markers RM17496 and RM6629, separated by a distance of about $300 \mathrm{~kb}$, in the Nipponbare genome. Considering the genotypes of the close marker genotypes, the threshold value for diagnosis as $\mathrm{S}$ or $\mathrm{R}$ was set between 5 and 6 . The results of diagnosis were highly consistent with the neighboring DNA markers around the Pikahei-1(t), even at the individual level. Only a very slight inconsistency in the phenotype was observed for a single close recombinant, 13-28, but other three recombinants at the same site showed a consistent phenotype (Fig. 4). Although from Fig. 4, this diagnosis seems to differentiate the R-homo individuals from the hetero 


\begin{tabular}{|c|c|c|c|c|c|c|c|c|c|c|c|c|c|c|c|}
\hline Markers & $\begin{array}{c}\text { RM } \\
17488\end{array}$ & $\begin{array}{l}970- \\
60 \mathrm{~K} 2\end{array}$ & $\begin{array}{c}\text { RM } \\
17494\end{array}$ & $\begin{array}{c}\text { RM } \\
17496\end{array}$ & $\begin{array}{c}970- \\
149 \mathrm{~K}\end{array}$ & N-SNP & $\begin{array}{c}\text { RM } \\
17501\end{array}$ & Symptom & $\begin{array}{l}645- \\
80 \mathrm{~K}\end{array}$ & $\begin{array}{c}\text { RM } \\
5473\end{array}$ & $\begin{array}{c}\text { RM } \\
3843\end{array}$ & $\begin{array}{c}\text { RM } \\
6629\end{array}$ & $\begin{array}{l}669- \\
40 \mathrm{~K}\end{array}$ & $\begin{array}{c}\text { RM } \\
3319\end{array}$ & $\begin{array}{c}\text { RM } \\
5611\end{array}$ \\
\hline $1--2$ & $\mathbf{R}$ & H & $\mathrm{H}$ & $\mathrm{H}$ & $\mathrm{H}$ & H & H & 5 & $\mathrm{H}$ & $\mathrm{H}$ & $\mathrm{H}$ & $\mathrm{H}$ & H & H & $\mathrm{H}$ \\
\hline $1--3$ & $\mathbf{R}$ & H & H & $\mathrm{H}$ & $\mathrm{H}$ & H & H & 5 & $\mathrm{H}$ & H & $\mathrm{H}$ & $\mathrm{H}$ & H & H & $\mathrm{H}$ \\
\hline $7--22$ & H & $R$ & $R$ & $R$ & $R$ & $R$ & $R$ & 2 & $R$ & $R$ & $R$ & $\mathbf{R}$ & $R$ & $\mathbf{R}$ & $\mathbf{R}$ \\
\hline $1--50$ & $\mathrm{~s}$ & H & H & $\mathrm{H}$ & H & H & H & 4 & $\mathrm{H}$ & $\mathrm{H}$ & $\mathrm{H}$ & $\mathrm{H}$ & H & H & H \\
\hline $4--12$ & $\mathrm{~S}$ & H & $\mathrm{H}$ & H & H & H & H & 4 & H & H & H & $\mathrm{H}$ & H & H & H \\
\hline $14--55$ & $\mathrm{~S}$ & H & H & $\mathrm{H}$ & $\mathrm{H}$ & H & H & 2 & H & H & H & H & H & H & H \\
\hline $3--42$ & s & s & $\mathrm{s}$ & $\mathrm{H}$ & $\mathrm{H}$ & H & H & 5 & H & H & $\mathrm{H}$ & H & $\mathrm{H}$ & H & $\mathrm{H}$ \\
\hline $5--37$ & s & s & $\mathrm{s}$ & $\mathrm{H}$ & $\mathrm{H}$ & H & H & 3 & $\mathrm{H}$ & $\mathrm{H}$ & $\mathrm{H}$ & $\mathrm{H}$ & H & $\mathrm{H}$ & H \\
\hline 6--6 & s & s & $\mathrm{s}$ & $\mathrm{H}$ & $\mathrm{H}$ & $\mathrm{H}$ & H & 5 & $\mathrm{H}$ & $\mathrm{H}$ & $\mathrm{H}$ & $\mathrm{H}$ & $\mathrm{H}$ & $\mathrm{H}$ & $\mathrm{H}$ \\
\hline $\begin{array}{ll}4--42 \\
\end{array}$ & $R$ & $R$ & $R$ & $\mathrm{H}$ & $\mathrm{H}$ & $\mathrm{H}$ & H & 5 & $\mathrm{H}$ & H & $\mathrm{H}$ & H & H & H & $\mathrm{H}$ \\
\hline 12--29 & $\mathbf{R}$ & $\mathbf{R}$ & $R$ & $\mathrm{H}$ & $\mathbf{H}$ & $\mathrm{H}$ & H & 3 & H & H & $\mathrm{H}$ & H & H & H & $\mathrm{H}$ \\
\hline $2--94$ & H & H & $\mathrm{H}$ & $\mathrm{S}$ & $\mathrm{s}$ & $\mathrm{S}$ & $\mathrm{S}$ & 7 & $\mathrm{~S}$ & s & $\mathrm{S}$ & $\mathrm{s}$ & $\mathrm{s}$ & $\mathrm{S}$ & $\mathrm{s}$ \\
\hline 3--79 & H & $\mathrm{H}$ & $\mathrm{H}$ & $\mathrm{S}$ & $\mathrm{S}$ & $\mathrm{S}$ & S & 8 & $\mathrm{~S}$ & S & $\mathrm{S}$ & s & $\mathrm{S}$ & $\mathrm{S}$ & $\mathrm{s}$ \\
\hline $4--44$ & H & H & H & S & S & $\mathrm{S}$ & S & 6 & S & $\mathrm{s}$ & S & s & $\mathrm{S}$ & $\mathrm{S}$ & s \\
\hline $\begin{array}{l}4--88 \\
\end{array}$ & H & H & $\mathrm{H}$ & $\mathrm{s}$ & s & S & $\mathrm{s}$ & 8 & $\mathrm{~s}$ & $\mathrm{~s}$ & $\mathrm{~s}$ & $\mathrm{~s}$ & $\mathrm{~s}$ & s & $\mathrm{s}$ \\
\hline 7--77 & $\mathrm{H}$ & $\mathrm{H}$ & $\mathrm{H}$ & s & s & $\mathrm{s}$ & $\mathrm{s}$ & 8 & $\mathrm{~s}$ & $\mathrm{~s}$ & s & $\mathrm{s}$ & s & $\mathrm{s}$ & $\mathrm{s}$ \\
\hline \begin{tabular}{|c|}
$8--40$ \\
\end{tabular} & $\mathrm{H}$ & H & $\mathrm{H}$ & $\mathrm{s}$ & $\mathrm{s}$ & $\mathrm{s}$ & $\mathrm{s}$ & 6 & s & $\mathrm{s}$ & s & $\mathrm{s}$ & s & $\mathrm{s}$ & $\mathrm{s}$ \\
\hline 12--39 & $\mathrm{H}$ & H & $\mathrm{H}$ & $\mathrm{s}$ & $\mathrm{s}$ & $\mathrm{s}$ & $\mathrm{s}$ & 8 & $\mathrm{~s}$ & $\mathrm{~s}$ & $\mathrm{~s}$ & $\mathrm{~s}$ & s & s & s \\
\hline $3--56$ & H & H & $\mathrm{H}$ & $\bar{H}$ & $\mathrm{~s}$ & s & $\mathrm{s}$ & 8 & $\mathrm{~s}$ & $\mathrm{~s}$ & $\mathrm{~s}$ & $\mathrm{~s}$ & s & s & s \\
\hline 6--47 & H & H & H & H & s & $\mathrm{s}$ & s & 7 & $\mathrm{~s}$ & s & $\mathrm{s}$ & $\mathrm{s}$ & s & S & s \\
\hline $\begin{array}{l}5--64 \\
\end{array}$ & $\mathrm{H}$ & H & $\mathrm{H}$ & $\mathrm{H}$ & $\mathbf{R}$ & $\mathbf{R}$ & $\mathbf{R}$ & 1 & $\mathbf{R}$ & $\mathbf{R}$ & $\mathbf{R}$ & $\mathbf{R}$ & $\mathbf{R}$ & $\mathbf{R}$ & $\mathbf{R}$ \\
\hline $\begin{array}{l}6--58 \\
\end{array}$ & $\mathbf{R}$ & $\mathbf{R}$ & $\mathbf{R}$ & $\mathbf{R}$ & $\mathrm{H}$ & $\mathbf{H}$ & $\mathrm{H}$ & 5 & $\mathrm{H}$ & H & $\mathrm{H}$ & H & H & $\mathrm{H}$ & $\mathrm{H}$ \\
\hline 1--76 & s & s & s & $\mathrm{s}$ & $\mathrm{H}$ & $\mathrm{H}$ & H & 5 & $\mathbf{H}$ & H & $\mathrm{H}$ & $\mathrm{H}$ & $\mathrm{H}$ & $\mathrm{H}$ & $\mathrm{H}$ \\
\hline 7-- 93 & s & s & $\mathrm{s}$ & s & $\mathbf{H}$ & $\mathrm{H}$ & $\mathrm{H}$ & 4 & $\bar{H}$ & H & $\mathrm{H}$ & $\mathrm{H}$ & $\mathrm{H}$ & $\mathrm{H}$ & H \\
\hline \begin{tabular}{|l|l}
$13--28$ \\
\end{tabular} & $\mathrm{~s}$ & s & s & $\mathrm{s}$ & H & $\mathrm{H}$ & H & 6 & H & H & $\mathrm{H}$ & H & H & $\mathrm{H}$ & H \\
\hline \begin{tabular}{|c|}
$9--70$ \\
\end{tabular} & s & $\mathrm{s}$ & s & $\mathrm{s}$ & $\mathrm{H}$ & H & H & 4 & $\mathrm{H}$ & $\mathrm{H}$ & $\mathrm{H}$ & $\mathrm{H}$ & $\mathrm{H}$ & $\mathrm{H}$ & $\mathbf{H}$ \\
\hline 9--87 & H & H & H & H & H & $\mathbf{R}$ & $\mathbf{R}$ & 2 & $\mathbf{R}$ & $\mathbf{R}$ & $\mathbf{R}$ & $\mathbf{R}$ & $\mathbf{R}$ & $\mathbf{R}$ & $\mathbf{R}$ \\
\hline $7--13$ & $\mathbf{R}$ & H & H & H & H & H & H & 5 & H & H & H & s & s & S & s \\
\hline
\end{tabular}

Fig. 4 Graphical genotype of the close markers around the Pikahei1(t) region, and the blast diagnosis scores of the close recombinants, selected from 1,439 siblings of the neighboring locus heterozygous plants, obtained by the tent inoculation and greenhouse evaluation system. This enabled diagnosis at the level of single plants, and even graphical genotyping of the close markers in close recombinants for this field resistance component. Symptom scores of six or more and of five or less were considered S and R, respectively, and were mostly consistent with the results of genotyping of the close markers. The

individuals, with threshold between 2 and 3, verification of the critical recombination of 9-87 may require additional experiments.

\section{Physical mapping of Pikahei-1(t) in Nipponbare genome}

To physically map the Pikahei-1(t) locus in the Nipponbare genome, the above identified close SSR markers were "landed" on three BAC clones, OSJNa0058K23, OSJNb0085C12, and OSJNa0053K19, in the Gramene and IRGSP database (Fig. 5). With annotation by GAAS analysis, 52 possible ORFs were identified in the region (Table 2). These included seven resistance gene analogs (RGAs) with an NBS-LRR domain. By PCR amplification of their counterparts from the Kahei genome, only RGAs 2 and 3 were properly amplified as full ORFs, and were located in the central region of graphical genotyping. Counterparts of RGAs 1, 4, and 6 were partially amplified, but their graphical genotypes were not related to the Pikaehei-1(t) region (data not shown). RGAs 5 and 7 were not amplified from symptoms also seemed to be dose-related, and a score of two or less seemed to correspond approximately to R homozygotes. The margins of recombination are indicated with a bold line. The region of Pikahei-1(t) is also marked with a bold rectangle covering the central markers and their genotypes. The heterozygotes and susceptible homozygotes are shown in light and dense hatching, respectively, including the corresponding symptom scores. The validity of diagnosis of the critical line 9-87 as R-homo requires confirmation in the next generation

the Kahei genome. The functions of other ORFs were mostly unknown, and only three were probably transposonrelated and were excluded from consideration. Although the RGAs are the most likely candidates, all the possibilities should still be considered, as the dominant FR gene has yet to be cloned.

\section{Discussion}

Field resistance, also known as quantitative resistance, especially against rice blast, has been studied and attempts have been made to introduce FR into practical cvs., especially by rice breeders, to achieve durability and wide-spectrum race specificity (Bonman 1992). However, the molecular identification of FRs as genes and introduction into elite cvs. have been hindered by their multigenicity and lack of methods to fine map the respective constitutive components. Even after dissecting their components genetically by QTL analysis of RI lines, fine mapping was difficult 


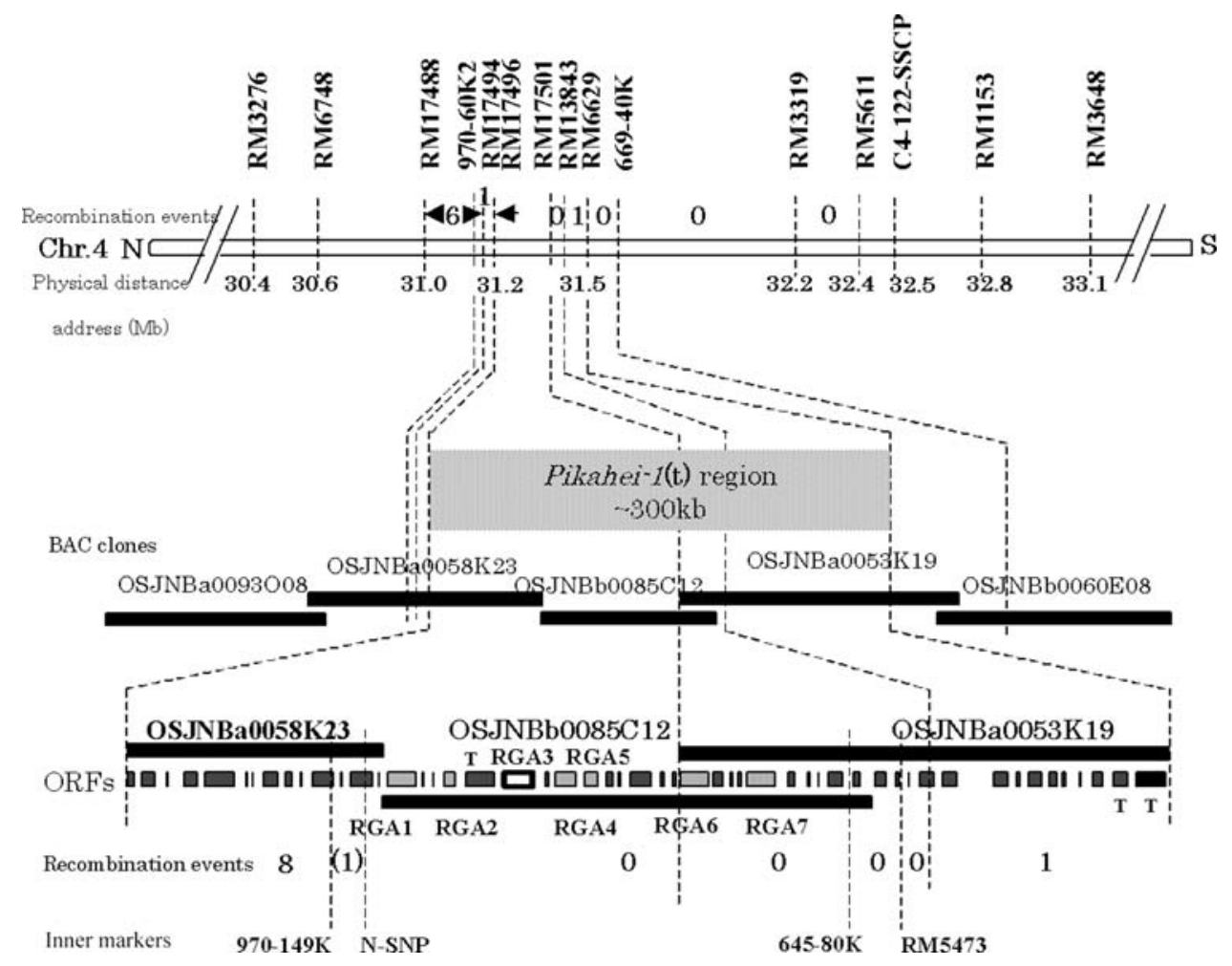

Fig. 5 Physical maps around the Pikahei-1(t) region on the long arm of chromosome 4 based on the Nipponbare RGP database. Marker names and recombination event numbers in the data, as presented in Fig. 4, are shown above the chromosome bar. Addresses on chromosome 4 in physical distances from the top are indicated below the chromosome bar in megabases $(\mathrm{Mb})$. The details of the Pikahei-1 $(\mathrm{t})$ region in the Nipponbare physical map are shown at the bottom with 52 predicted ORFs, among which the transposon-related three ORFs are indicated by $\mathrm{T}$ on the right end. The new markers in the Pikahei-1(t) region at the bottom were developed from SNPs between Nipponbare, as

with the conventional upland late sowing method, because it requires large areas of special isolated fields for diagnosis, and the number of lines that can be diagnosed in several replicates is still limited; especially, field diagnosis can only be performed once a year.

We attempted to fine map the most highly contributing FR QTL of domestic upland rice cv. Kahei in Kyushu, qRBFR4-1 (Miyamoto et al. 2001) first by the near conventional upland late sowing method using the RI lines with residual heterozygosity at $q B F R 4-1$, but homozygous, mostly susceptible, with the other QTLs. By selecting 96 susceptible $\mathrm{F}_{7}$ lines from this field analysis, the tentative locus was assigned to an area of $32-33 \mathrm{Mb}$ from the top on chromosome 4, near the end of the long arm, but a yearly repeat to confirm the result was hindered by poor field conditions, seemingly due to long repeated upland cultivation of rice. Therefore, we applied a new greenhouse diagnosis system to evaluate FR against rice blast. This is a half-natural blast inoculation system in the greenhouse developed for screening recessive blast resistant mutants (Kawasaki shown in Table 3, and the possible recombination event estimated from 9-87 diagnosed as R-homo in Fig. 4 is shown in parentheses. All annotations of the ORFs and corresponding RGAs are shown in Table 2. There were seven candidate RGAs (RGA 1-7) as possible counterparts of the actual Pikahei-1(t) in the resistant cv. genome. By graphical genotyping of the RGAs with other markers, only parts of RGAs 2 and 3 were shown to be located in the Pikahei-l(t) region and are shown by blank boxes, and RGAs 1,4 , and 6 were assigned outside the region. RGAs 5 and 7 were not properly amplified in the Kahei genome

et al. 2008) from culture-mutated $\mathrm{M}_{2}$ rice plant populations (Miyao et al. 2003). Seedlings 2-3 weeks old were seminaturally infected from diseased plants within a tent with sufficient dew formation caused by daily fluctuation of temperature of $>5-7^{\circ} \mathrm{C}$. Spores showed sufficiently uniform dispersal without displacing the seedling mats during the covering time. This system worked very consistently and reproducibly, even in the winter or summer both of which are normally avoided as non-optimal seasons for blast inoculation, if the greenhouse temperature control can provide the prescribed conditions. In these seasons, it is often difficult to achieve reproducible inoculation using a conventional spray inoculation system even in well-equipped greenhouses and with a good humid chamber.

As shown in Fig. 2, this inoculation system can provide very high-density lesions by increasing the inoculation period (5-7 days) with a high degree of reproducibility, often difficult in the conventional spray inoculation system. It is possible to achieve any level of infection of the test plants by changing the inoculation (tent-covering) period. 
Table 2 Annotation data of the putative ORFs in the Pikahei-1(t) region in the Nipponbare genome database

\begin{tabular}{|c|c|c|}
\hline ORF no & Proteins coded by predicted genes & Predicted length (bp) \\
\hline 1 & Unknown protein & 208 \\
\hline 2 & Putative F-box family protein/WD-40 repeat family protein & 684 \\
\hline 3 & Hypothetical protein & 28 \\
\hline 4 & $\begin{array}{l}\text { Putative ATBAG1 (ARABIDOPSIS THALIANA BCL-2-ASSOCIATED } \\
\text { ATHANOGENE 1); protein binding }\end{array}$ & 504 \\
\hline 5 & $\begin{array}{l}\text { Putative Canalicular multispecific organic anion transporter } 1 \\
\text { (ATP-binding cassette sub-family C member } 2 \text { ) } \\
\text { (multidrug resistance-associated protein } 2 \text { ) } \\
\text { (canalicular multidrug resistance protein) } \\
\text { (epithelial basolateral chloride conductance regulator) }\end{array}$ & 1,636 \\
\hline 6 & Hypothetical protein & 79 \\
\hline 7 & Hypothetical protein & 35 \\
\hline 8 & Putative remorin family protein & 659 \\
\hline 9 & Hypothetical protein & 187 \\
\hline 10 & Hypothetical protein & 27 \\
\hline 11 & Putative SIT4 phosphatase-associated family protein & 714 \\
\hline 12 & Unknown protein similar to Os04g0620600 & 93 \\
\hline 13 & Putative tobacco nucleolin & 729 \\
\hline 14 & Hypothetical protein similar to Os04g0620800 & 117 \\
\hline 15 & Putative NBS-LRR disease resistance protein homolog (RGA1) & 1,435 \\
\hline 16 & Hypothetical protein & 51 \\
\hline 17 & Unknown protein & 162 \\
\hline 18 & Putative NB-ARC domain-containing protein, expressed (RGA2) & 376 \\
\hline 19 & Putative MuDR family transposase domain containing protein & 1,357 \\
\hline 20 & Putative NBS-LRR disease resistance protein homolog (RGA3) & 1,716 \\
\hline 21 & Putative polyprotein & 125 \\
\hline 22 & Putative XA1 (RGA4) & 1,084 \\
\hline 23 & Putative XA1 (RGA5) & 648 \\
\hline 24 & Unknown protein & 339 \\
\hline 25 & Hypothetical protein & 120 \\
\hline 26 & Putative SWIM zinc finger family protein & 1,152 \\
\hline 27 & Hypothetical protein & 137 \\
\hline 28 & Hypothetical protein & 121 \\
\hline 29 & Putative XA1 (RGA6) & 1,886 \\
\hline 30 & Unknown protein similar to PREDICTED OSJNBa0056O06.23 gene product & 303 \\
\hline 31 & Hypothetical protein & 148 \\
\hline 32 & Unknown protein similar to CDR1 & 193 \\
\hline 33 & Putative XA1 (RGA7) & 1,822 \\
\hline 34 & Unknown protein similar to PREDICTED OSJNBa0056O06.23 gene product & 457 \\
\hline 35 & Unknown protein & 147 \\
\hline 36 & Hypothetical protein & 12 \\
\hline 37 & Putative amine oxidase family protein & 502 \\
\hline 38 & Hypothetical protein & 103 \\
\hline 39 & Putative exonuclease family protein & 261 \\
\hline 40 & Hypothetical protein & 41 \\
\hline 41 & Hypothetical protein & 73 \\
\hline 42 & Putative (S)-2-hydroxy-acid oxidase (EC 1.1.3.15) & 319 \\
\hline 43 & Putative (S)-2-hydroxy-acid oxidase (EC 1.1.3.15) & 429 \\
\hline
\end{tabular}


Table 2 continued

\begin{tabular}{llr}
\hline ORF no & Proteins coded by predicted genes & Predicted length (bp) \\
\hline 44 & $\begin{array}{l}\text { Putative Aminomethyltransferase, mitochondrial precursor } \\
\text { (Glycine cleavage system T protein) (GCVT) }\end{array}$ & 355 \\
45 & Hypothetical protein & 54 \\
46 & Unknown protein & 396 \\
47 & Hypothetical protein & 177 \\
48 & Putative microtubule-associated protein 1 light chain 3 & 120 \\
49 & Hypothetical protein & 74 \\
50 & Hypothetical protein & 434 \\
51 & Putative gypsy-type retrotransposon RIRE2 protein & 833 \\
52 & Putative gag-pol precursor & 1,998 \\
\hline
\end{tabular}

Although Nipponbare does not have a functional Pikahei-1(t) gene, there are seven probable counterpart RGAs, indicated by bold letters, and numbered in parentheses corresponding to Fig. 5. The transposon-related proteins in italics were excluded from further consideration

Table 3 PCR primer sequences of newly developed SNP and HEGS-SSCP markers near Pikahei-1(t) for the Kahei/Nipponbare map

\begin{tabular}{lll}
\hline Primer & Forward & Reverse \\
\hline 970-60K2 & 5'CCACGAAAAACGGAATAAGG3' & 5'GCAAATGAAGCACAAAAGCA3' $^{\prime}$ \\
970-149K & 5'TTTGTTGAAGCTGCTGGATG3' & 5'TATGCACTTTGTGGCTCGAC3' $^{\prime}$ \\
N-SNP & 5'TTCAGCGGTGGAAGAGACTT3' & 5'ATCAAGTCCAAGCAGCGAGT3' \\
$645-80 \mathrm{~K}$ & 5'TTGGTTTCATGCAGAAGCAG3' & 5'GTAGCGGCTAGCCATGTTGT3' $^{\prime}$ \\
669-40K & 5'AAGGGACCGTGTGCTTAGTG3' & 5'CCAGATCTCCCTATGCTTCG3' $^{\prime}$ \\
C4-122-SSCP & 5'GACGACAAGTCCAGTTGCATT3' & 5'TCACCAGTTCCAAACACTCG3' \\
\hline
\end{tabular}

Their locations are indicated in Fig. 5. They were developed from sequences of Nipponbare

This allows quantification of the disease resistance of the strains or even of individual plants, as shown in Fig. 4, which is difficult with the standard spray inoculation method. Thus, application of this system for Pikahei-l(t) enabled diagnosis at the level of single plants, and the mapping resolution could be increased in proportion to the sample numbers. Therefore, QTL analysis (Fig. 3) and graphical genotyping (Fig. 4) were possible in the greenhouse system. Thus, although recombination around the target gene was suppressed, with 1439 samples the Pikahei-1(t) region was narrowed down to within a region of $300 \mathrm{~kb}$ (Fig. 5), around 31.2-31.5 Mb on chromosome 4 from the top end. This region was shifted slightly from the above assigned region based on limited field assay data, suggesting insufficient accuracy in the limited sampling diagnosis. This region is close to other rice blast FR QTLs: one from $O$. rufipogon and $q B R 4-2$ from Owarihatamochi. These genes probably form a cluster as in the case of other blast resistance genes, such as Pik and Pita groups.

Previously, the number of plants in study populations for rice FR QTL analyses has not exceeded about 300 (Wang et al. 1994; Chen et al. 2000; Bagali et al. 2000; Miyamoto et al. 2001; Fukuoka and Okuno 2001; Sirithunya et al. 2002; Zenbayashi et al. 2002; Fukuta et al. 2004; Tabien et al. 2002; Liu et al. 2004; Talukder et al. 2004, 2005; Wu et al. 2005; Nguyen et al. 2006; Sato et al. 2006). Here, we analyzed Pikahei-1(t) with more than ten times the number of samples than conventional methods in a very short time ( $\sim 5$ weeks), although this was partly due to the strong resistance conferred by Pikahei-1(t). This system will be applicable even for weaker FR QTL analyses and for breeding, using line evaluations in the seedling mats in combination with QTL analysis.

A physical map of the region around Pikahei-1(t) was constructed based on Nipponbare BAC clones (Fig. 5). The GAAS data of the region revealed the presence of seven candidates of RGAs, probably including the counterpart of the resistance gene in Kahei. The clustering of these several RGAs indicates that this region constitutes a rice blast R-gene cluster comparable to those of Pik or Pita in rice, as suggested by the co-localization of other blast FR QTLs (Fig. 3). Such clustering of RGAs in the center of the region is surprisingly similar to the Pik cluster region in Nipponbare (Xu et al. 2008). By graphical genotyping of these seven RGAs with their SNPs, RGAs 1, 4, and 6 were shown to be located outside of the region (data not shown), probably excluding them from the candidate counterpart list. This also indicates a highly mutable character of this region of the genome, often observed in various R-gene clusters (Michelmore and Meyers 1998). 
From these results, as a hypothesis, we are speculating that the most of the QTLs of the conventional multi-component FRs are NBS-LRR type R-genes with weak defense responses than the true resistance genes: i.e., FRs are natural gene pyramiding of WEAK R-genes. That will secure natural suppression of $A v r$-mutated races by the competition with wild-type races because Avr-mutations are expected to lower the fitness value of the pathogen. On the contrary, the true resistances may be providing sterile condition without competition, for the Avr-mutated races, by completely suppressing wild-type races, thus making the true resistance less durable.

However, as the possibility of other ORFs as candidate counterparts could not be excluded based on the present results, we are currently increasing the population of hetero-siblings to further narrow down the region. In parallel, a new Kahei genome BAC library is being constructed, from which we hope to be able to clone and identify the Pikahei-1 $(\mathrm{t})$ gene by constructing a physical map of Kahei genome around the gene in the near future.

Acknowledgments We thank Dr Miyamoto and Dr Hirasawa for supplying the RILs used in this study. We also appreciate Dr Hayashi for sharing the fungal line Kyu9439013 for diagnosis in the greenhouse.

Open Access This article is distributed under the terms of the Creative Commons Attribution Noncommercial License which permits any noncommercial use, distribution, and reproduction in any medium, provided the original author(s) and source are credited.

\section{References}

Bagali PG, Hittalmani S, Shashidhar SY, Shashidhar HE (2000) Identification of DNA markers linked to partial resistance for blast disease in rice across four locations. In: Tharreau D, Lebrun MH, Talbot NJ, Notteghem JL (eds) Advances in rice blast research. Kluwer Academic Publishers, Dordrecht, pp 34-44

Bonman JM (1992) Durable resistance to rice blast disease-environmental in influences. Euphytica 63:115-123

Chen DH, Nelson RJ, Wang GL, Inukai T, Mackill DJ, Ronald PC (2000) Characterization of blast resistance in the durable resistant rice cultivar Moroberekan. In: Tharreau D, Lebrun MH, Talbot NJ, Notteghem JL (eds) Advances in rice blast research. Kluwer Academic Publishers, Dordrecht, pp 17-27

Ezuka A (1972) Field resistance of rice varieties to rice blast disease. Rev Plant Prot Res 5:1-21

Fukuoka S, Okuno K (2001) QTL analysis and mapping of Pi21, a recessive gene for field resistance to rice blast in Japanese upland rice. Theor Appl Genet 103:185-190

Fukuoka S, Kudo S, Okuno K (2003) Genetic analysis of qBR4-2, a QTL for field resistance to rice blast using backcrossed progeny lines. Breed Res 5(Suppl. 2):332

Fukuoka S, Shimizu T, Saka N, Koga H, Ebana K, Hirochika H, Yano M, Okuno K. (2007) Molecular cloning of a QTL, pi21, controlling field resistance to blast in rice. Plant \& Animal Genomes XV Conference, San Diego, CA, W369

Fukuta Y, Yanoria MJT, Mercado-Escueta D, Ebron LA, Fujita A, Araki E, Khush GS (2004) Quantitative traits loci (QTL) reactions to rice blast isolates from Japan and Philippines. In: Kawasaki S (ed) Rice blast: interaction with rice and control. Kluwer Academic Publishers, Dordrecht, pp 113-121

Hayashi N (2005) MAFF microorganism genetic resources manual, vol vol. 18. Rice blast fungus, National Institute of Agrobiological Sciences, Tsukuba

Hirabayashi H, Sato H, Kato H, Ando I, Imbe T, Ogawa T (2005) Mapping of a partial resistance gene for rice blast in Oryza rufipogun (IRGC-Acc104814). Breed Res 7(Suppl. 1-2):244

International Rice Genome Sequencing Project (2005) The map-based sequence of the rice genome. Nature 436:793-800

Ishizaki K, Hoshi T, Abe S, Sasaki Y, Kobayashi K, Kasaneyama H, Matsui T, Azuma S (2005) Breeding of blast resistant isogenic lines in rice variety Koshihikari and evaluation of their characters. Breeding Sci 55:371-377

Iwata M, Umemura K, Midoh N (2004) Probenazole (Oryzemate ${ }^{\circledR}$ )a plant defense activator. In: Kawasaki S (ed) Rice blast: interaction with rice and control. Kluwer Academic Publishers, Dordrecht, pp 163-171

Kawasaki S, Awato H, Takahashi A, Xu X, Miyao A, Kato H, Hirochika H (2008) Development of an efficient screening system of recessive rice blast resistance mutants and its application. Breed Res 10(Suppl. 1): 162

Liu B, Zhang SH, Zhu XY, Yang QY, Wu SZ, Mei MT, Mauleon R, Leach J, Mew T, Leung H (2004) Candidate defense genes as predictors of quantitative blast resistance in rice. Mol Plant Microbe Interact 17:1146-1152

Michelmore RW, Meyers BC (1998) Clusters of resistance genes in plants evolve by divergent selection and a birth-and-death process. Genome Res 8:1113-1130

Miyamoto M, Yano M, Hirasawa H (2001) Mapping of quantitative trait loci conferring blast field resistance in the Japanese upland rice variety Kahei. Breed Sci 51:257-261

Miyao A, Tanaka K, Murata K, Sawaki H, Takeda S, Abe K, Shinozuka Y, Onosato K, Hirochika H (2003) Target site specificity of the Tos 17 retrotransposon shows a preference for insertion within genes and against insertion in retrotransposon-rich regions of the genome. Plant Cell 15:1771-1780

Nguyen TT, Koizumi S, La TN, Zenbayashi KS, Ashizawa T, Yasuda N, Imazaki I, Miyasaka A (2006) Pi35(t), a new gene conferring partial resistance to leaf blast in the rice cultivar Hokkai 188. Theor Appl Genet 113:697-704

Sato H, Takeuchi Y, Hirabayashi H, Nemoto H, Hirayama M, Kato H, Imbe T, Ando I (2006) Mapping QTLs for field resistance to rice blast in the Japanese upland rice Variety Norin 12. Breed Sci 56:415-418

Sirithunya P, Tragoonrung S, Vanavichit A, Pa-In N, Vongsaprom C, Toojinda T (2002) Quantitative trait loci associated with leaf and neck blast resistance in recombinant inbred line population of rice (Oryza sativa). DNA Res 9:79-88

Tabien RE, Li Z, Paterson AH, Marchetti MA, Stansel JW, Pinson SRM (2002) Mapping QTLs for field resistance to the rice blast pathogen and evaluating their individual and combined utility in improved varieties. Theor Appl Genet 105:313-324

Talukder ZI, Tharreau D, Price AH (2004) Quantitative trait loci analysis suggests that partial resistance to rice blast is mostly determined by race-specific interactions. New Phytol 162:197209

Talukder ZI, McDonald AJS, Price AH (2005) Loci controlling partial resistance to rice blast do not show marked QTL $\times$ environment interaction when plant nitrogen status alters disease severity. New Phytol 168:455-464

Wang GL, Mackill DJ, Bonman JM, McCouch SR, Champoux MC, Nelson RJ (1994) RFLP mapping of genes conferring complete and partial resistance to blast in a durably resistance rice cultivar. Genetics 136:1421-1434 
Wang S, Basten CJ, Zeng ZB (2006) Windows QTL Cartographer 25. Department of Statistics, North Carolina State University, Raleigh, NC (http://statgenncsuedu/qtlcart/WQTLCarthtm)

Wu JL, Fan YL, Li DB, Zheng KL, Leung H, Zhuang JY (2005) Genetic control of rice blast resistance in the durably resistant cultivar Gumei 2 against multiple isolates. Theor Appl Genet 111:50-56

Xu X, Kawasaki S, Fujimura T, Wang CT (2005) A protocol for highthroughput extraction of DNA from rice leaves. Plant Mol Biol Rep 27:291-295
Xu X, Hayashi N, Wang CT, Kato H, Fujimura T, Kawasaki S (2008) Efficient authentic fine mapping of the rice blast resistance gene $P i k$ - $h$ in the Pik cluster, using new Pik-h-differentiating isolates. Mol Breed DOI 10.1007/s11032-008-9175-5.

Zenbayashi K, Ashizawa T, Tani T, Koizumi S (2002) Mapping of the QTL (quantitative trait locus) conferring partial resistance to leaf blast in rice cultivar Chubu 32. Theor Appl Genet 104:547-552 